\title{
DIVING BEHAVIOR OF THE EMPEROR PENGUIN, APTENODYTES FORSTERI
}

\author{
G. L. Kooyman, C. M. Drabek, R. Elsner, and W. B. Campbeli
}

ONE of the most unexpected discoveries in the avian world was the breeding of Emperor Penguins during the antarctic winter night (Wilson, 1905: 488). The large size of the chick at fledging and the time required for this development forces the Emperor Penguin to lay its single egg in late May and June (Stonehouse, 1953; Prévost, 1961) and incubate it through the antarctic night. The rookeries are established on fast sea ice, no formal nest is built, and the adult male incubates the egg in his brood pouch supported on his feet. The newly hatched chick is similarly maintained. Fledging does not occur until late December, and from March through April, depending on the latitude, the birds are again returning to the rookeries to form pairs and breed. Because of these reproductive commitments no other bird or mammal species is so obligated to remain in close proximity to the antarctic continent and the fast sea ice that borders its shores. This means that Emperor Penguins not only dive and feed during winter darkness, as other antarctic penguins do, but at times must do so in heavy pack ice and possibly have to do so even under fast ice, conditions that other penguins seldom, if ever, encounter. These features plus the fact that this species is the largest of diving birds make information about such diving capacities as submersion durations, depth, and swimming speed of especial interest.

\section{Materials and Methods}

We were able to study and measure dives of birds in both natural and experimental conditions. Observations on natural dive patterns and group diving behavior were obtained at Cape Royds in 1967, in the icebreaker channel between Cape Royds and Cape Armitage in 1967, and near the rookery at Cape Crozier in 1968 and 1969 (Figures 1 and 2). The usual method was to watch the birds' surface behavior from the edge of the ice and to time their dives. On three different occasions it was possible 1) to study their underwater behavior by lying at the ice edge and watching them dive below us, 2) to observe them while diving with scuba, and 3) in 1969 at Cape Crozier to suture small ( $4.5 \mathrm{~g})$ capillary Teflon depth-recorders superficially to the back of the necks of birds grouped at the edge of the ice. These birds later entered the water for what appeared to be feeding dives; 2 to 3 hours after attaching the depth tubes the birds were recaptured and the recorders removed.

The depth-recorders function on the same principle as those developed by Lord Kelvin in 1878 except the capillary tube is made of Teflon rather than glass (Fryer, 1958). Essentially it is a 61-cm coil of tubing, sealed at one end and coated on the inside with a water soluble dye that leaves a ring at maximum compression.

Experimental dives were conducted several miles offshore and northwest of Cape Armitage at a station that consisted of a heated hut over a man-made hole in annual sea ice. These experiments were conducted during three different austral summers, 

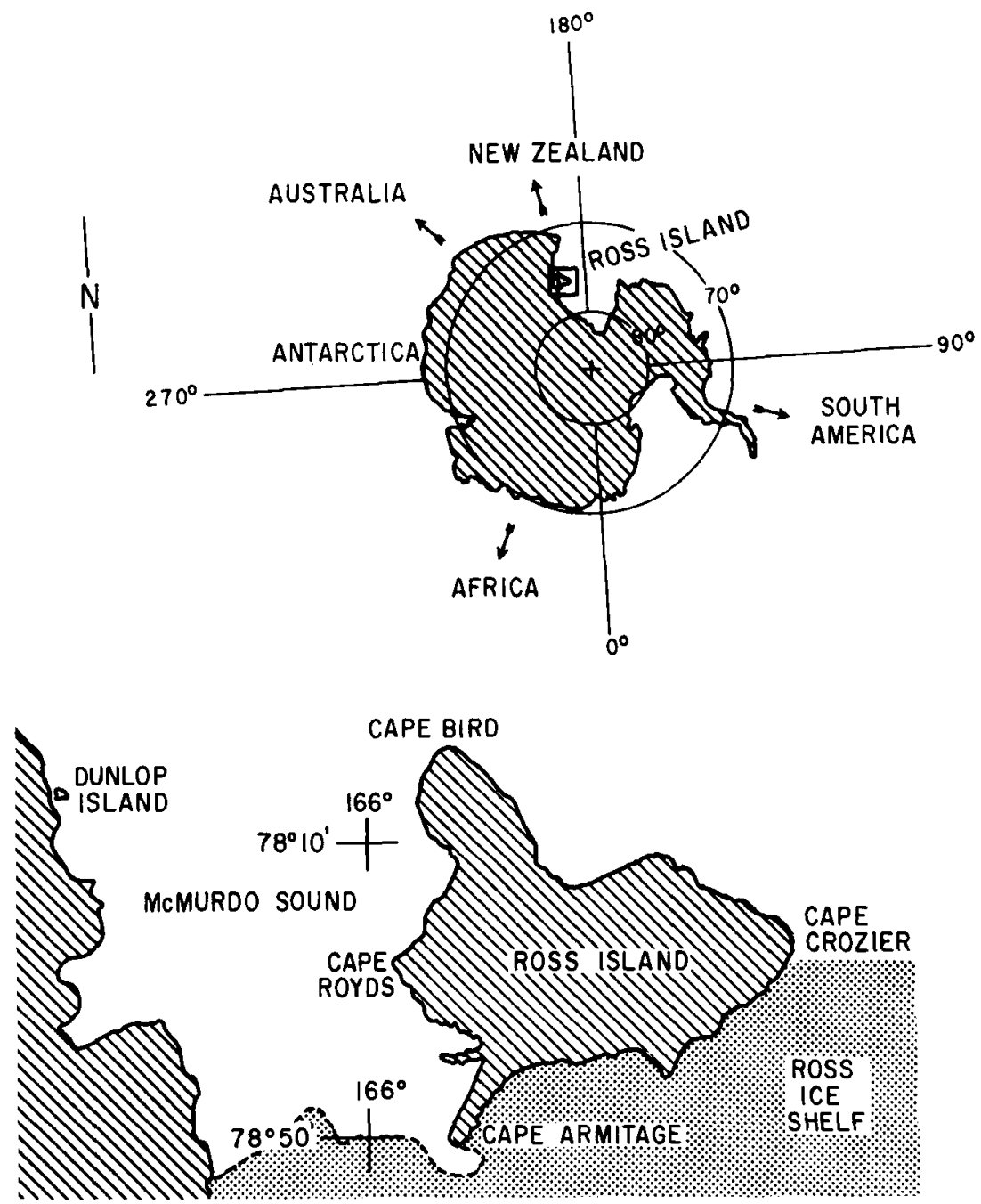

Figure 1. Locality map of the field studies. In November of 1963 and 1967 annual sea ice extended north of the Ross Ice Shelf to Cape Royds, and in 1968 and 1969 it was as far north as Cape Bird. Birds were studied diving under natural conditions at Cape Royds and Cape Crozier. Experimental dives were conducted a few miles offshore from Cape Armitage and the birds for these studies were collected at Cape Royds in 1967 and Cape Bird in 1968.

1963, 1967, and 1968, and sea ice thickness varied from 1.5-3.9 m. Techniques and instruments employed were the same as those for the Weddell seal, Leptonychotes weddelli (Kooyman, 1965, 1968). In brief, the birds were released at a hole so isolated that they had to return to it after each dive. A sub-ice observation chamber was used to watch the birds during most of the experiments. Diving depth and 


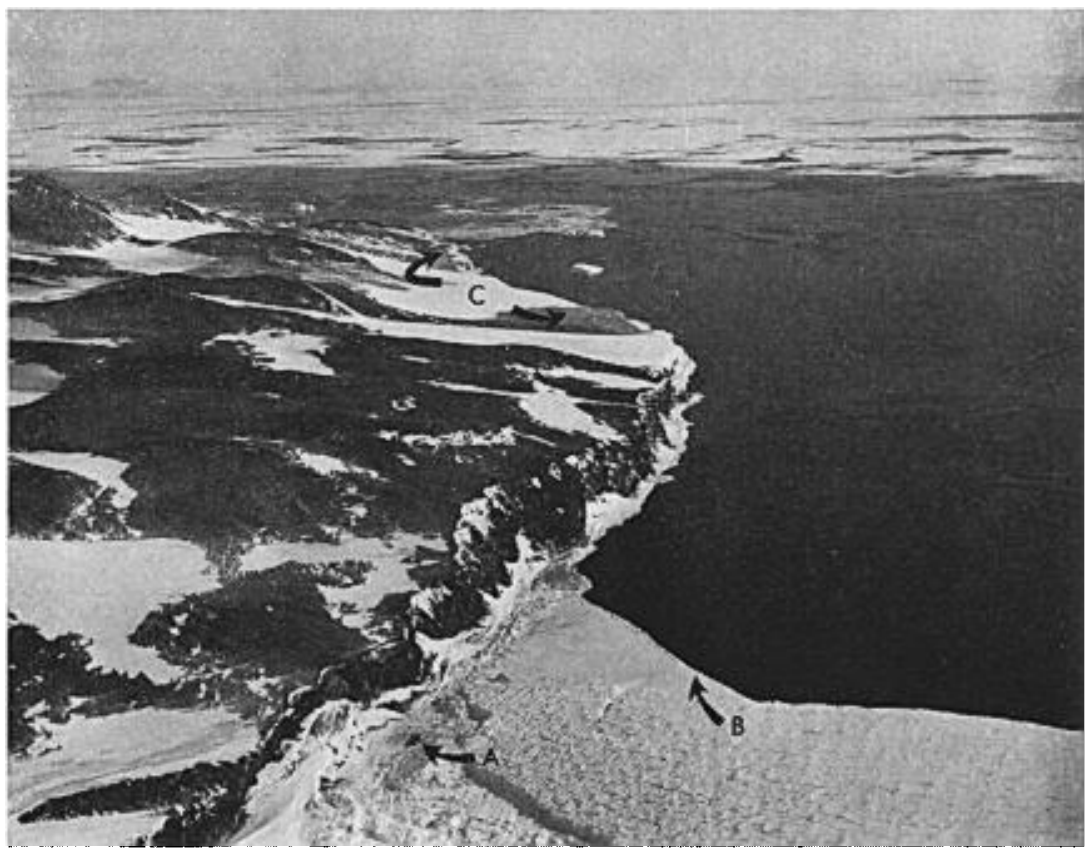

Figure 2. Aerial photo of Cape Crozier, Ross Island, Antarctica in November 1969. The black cliffs are about $150 \mathrm{~m}$ high. The dark area, A, is an Emperor Penguin rookery of about 500 chicks and adults. B is the sea ice foot where the deep diving measurements were obtained. $\mathrm{C}$ is the East and West Crozier Adélie Penguin rookery.

depth change rates were obtained with depth-time recorders and glass capillary depth tubes. The glass capillary tubes were much the same as the Teflon capillary tubes mentioned above. In this experimental situation the tubes were tied to the foot and removed usually after each dive while the bird was resting in the water. The depth-time recorder used was a clock and pressure gauge arranged to record pressure continuously against time on a smoked glass disk. The entire unit was housed in a water-tight aluminum cylinder. The total out-of-water weight was $700 \mathrm{~g}$. A 1.9-cm wide cotton webbing halter was placed on the penguin to which the depthtime recorder was attached by means of quick-release snaps.

Swimming speeds were obtained by training the birds to swim between two holes $27 \mathrm{~m}$ apart. The bird was released into the station hole where it dived until it found the other hole, which was not covered by a hut. After finding the outdoor hole the bird swam to it immediately whenever released in the station hole. During these experiments an observer always watched from the sub-ice observation chamber, which was placed between the two holes, to determine whether the birds swam directly to the other hole and to plot visually the profile of the dive and record the wingbeat rate. The observer was aided in preparing his profile plots by a line with markings at 3-m intervals hanging from the entrance. All snow was removed from the ice for a 30-m radius from the hut and water transparency was such that the observer could easily see both the entrance hole, $6 \mathrm{~m}$ away, and the exit hole, $21 \mathrm{~m}$ away. 


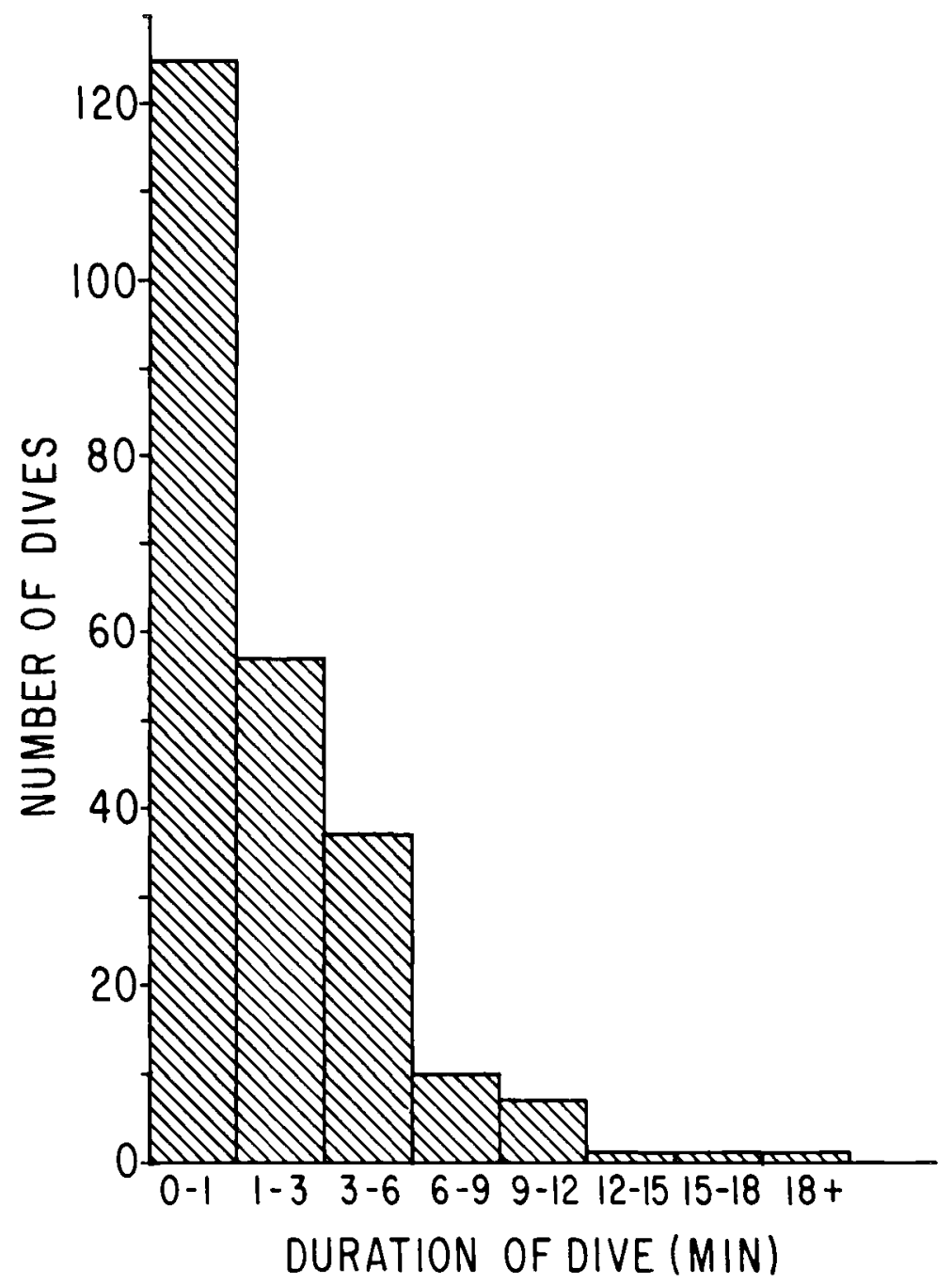

Figure 3. Histogram analysis of 238 dive durations obtained from 10 adult birds.

All birds for the experimental dives were collected from groups gathering at the ice edge, which was located at Cape Royds in 1967 and Cape Bird in 1968. Only two birds at a time were captured and flown to the dive station, 25 to $50 \mathrm{~km}$ south of open water. Experiments were not begun until the following day, and the holding pen was a $1.2 \times 3.7-\mathrm{m}$ plywood box with a snow-covered floor. Respiration rates and other respiratory patterns were obtained by direct observations of birds at the station hole. The birds weighed from 21.3-29.5 kg with a mean weight of $24.5 \mathrm{~kg}$. Sex differences were not determined. 


\section{Results}

\section{Diving Capacities}

Duration.--Dive durations of birds in natural conditions are difficult to time precisely because they dive in groups and individual birds are impossible to single out. If the whole group is treated as a single unit, the result is approximately the average submergence of all birds. When we timed birds this way and were reasonably confident that only one group was being measured, we obtained durations ranging from 2.5 to nearly 9 minutes. All were instances during which the birds appeared to be feeding.

A total of 238 dive times were measured during the experimental studies at the dive station. Most of the dives were less than 1 minute (Figure 3), and many of these short dives represented the penguin's attempts to get out of the ice hole by diving to about $3 \mathrm{~m}$, ascending rapidly, and leaping clear of the water. The majority of dives from 1-6 minutes represented exploratory forays by the birds in the vicinity of the hole. During these dives they would investigate the sub-ice chamber, attempt to pierce through the thinner, but impenetrable ice where the chamber tube passed through the ice, and peruse bright areas in the ice. They would also go to depths on these dives often beyond the range of the viewer. Dive durations in excess of 6 minutes were also exploratory in nature, but in these cases they were probably out of visual contact with the station hole and chamber for portions of the dive, and their length is possibly related to the degree of disorientation and difficulty in relocating the hole. The longest dive recorded was one where the bird never returned, although it was seen swimming near the chamber after 18 minutes submersion.

Depth.-Almost all depth measurements were obtained with small capillary depth tubes, weighing only a few grams and offering little resistance to swimming, and it is unlikely that they had much of an inhibiting effect during the dives. Because the birds at the experimental station were diving alone, under thick ice, and in strange surroundings, they were probably more interested in obtaining information about the under-ice configuration than diving deeply. As a result, the maximum dive measured of $38 \mathrm{~m}$ is much less than the depth estimate of $265 \mathrm{~m}$ we obtained for birds diving under more normal conditions (Tables 1 and 2).

Descent and ascent rates.-These rates were measured in two ways: with a depth-time recorder that gives a continuous record of depth against time for the entire dive; and by calculating the average depth-time change rate for the entire dive when the submersion time and maximum depth are known. The latter method is necessarily conservative because any time-consuming deviations by the bird are part of the calculation. The 
TABLE 1

Depth Mrasurements of Individuals Diving Singly at the Experimental Dive Station ${ }^{1}$

\begin{tabular}{ccccc}
\hline & \multicolumn{4}{c}{ Depth in meters } \\
\cline { 2 - 5 } Penguin & $0-10$ & $10-20$ & $20-30$ & $30-40$ \\
\hline B & 6 & 13 & 22 & 38 \\
& 4 & 15 & 22 & 30 \\
& 7 & 15 & 24 & \\
& 7 & 15 & 24 & \\
D & 8 & 15 & 20 & \\
& 8 & 10 & 22 & 32 \\
F & 6 & 18 & 23 & \\
& & 15 & 24 & \\
G & & 10 & & \\
M & 5 & 12 & 26 & \\
Total & 3 & 11 & & 4 \\
& & 9 & & \\
\end{tabular}

${ }^{1}$ Depths expressed in meters for convenience of conversion to pressure, $10 \mathrm{~m}$ of depth equals approximately 1 atmosphere of pressure.

maximum calculated depth change rate was $72 \mathrm{~m} / \mathrm{min}$ and the maximum measured rate was approximately $120 \mathrm{~m} / \mathrm{min}$ (Table 3). It should be noted that when the depth change of $120 \mathrm{~m} / \mathrm{min}$ (about $4.5 \mathrm{mph}$ ) was determined the penguin was encumbered by a harness and depth-time recorder weighing $700 \mathrm{~g}$. That the depth-time recorder exerted a significant drag on the penguins was confirmed by the chamber observers who noted an obvious increase in swimming effort when the unit was attached. When the instrument packs were on the birds, they seemed much more active and excited than birds not instrumented, consequently we were probably measuring escape or avoidance velocities of the birds. The exceptionally high rates of change were ascents from shallow depths where

TABLE 2

Depth Measurements of Penguins Diving in Groups at Cape Crozter ${ }^{1,2}$

\begin{tabular}{cc}
\hline Penguins & Depth in meters \\
\hline 5 & 7 \\
7 & 75 \\
10 & 265 \\
14 & 240 \\
15 & 130 \\
18 & 45 \\
\hline
\end{tabular}

${ }^{1}$ Six of the 24 birds with recorders were recovered, all within 3 hours.

2 Maximum depth of $265 \mathrm{~m}$ equals 870 feet. 
TABLE 3

Descent and Ascent Rates ${ }^{1}$

\begin{tabular}{|c|c|c|c|c|c|c|}
\hline \multirow[b]{2}{*}{ Penguin } & \multicolumn{3}{|c|}{ Descent } & \multicolumn{3}{|c|}{ Ascent } \\
\hline & Depth & $\begin{array}{l}\text { Time } \\
\text { (sec) }\end{array}$ & $\begin{array}{c}\text { Rate } \\
(\mathrm{m} / \mathrm{min})\end{array}$ & Depth & $\begin{array}{l}\text { Time } \\
(\mathrm{sec})\end{array}$ & $\begin{array}{c}\text { Rate } \\
(\mathrm{m} / \mathrm{min})\end{array}$ \\
\hline $\begin{array}{c}\mathrm{D} \\
\text { (Measured) }\end{array}$ & $\begin{array}{r}15 \\
11 \\
5\end{array}$ & $\begin{array}{l}47 \\
30 \\
11\end{array}$ & $\begin{array}{l}19 \\
25 \\
27\end{array}$ & $\begin{array}{r}10 \\
7\end{array}$ & $\begin{array}{r}9 \\
11\end{array}$ & $\begin{array}{l}67 \\
38\end{array}$ \\
\hline$\underset{\text { (Measured) }}{\mathbf{F}}$ & $\begin{array}{r}12 \\
11 \\
9 \\
5\end{array}$ & $\begin{array}{l}8 \\
8 \\
7 \\
5\end{array}$ & $\begin{array}{l}90 \\
85 \\
80 \\
60\end{array}$ & $\begin{array}{r}12 \\
6 \\
5\end{array}$ & $\begin{array}{l}8 \\
3 \\
3\end{array}$ & $\begin{array}{r}90 \\
120 \\
100\end{array}$ \\
\hline$\stackrel{\text { B }}{\text { (Calculated) }}$ & $\begin{array}{l}14 \\
17 \\
17 \\
18\end{array}$ & $\begin{array}{l}32 \\
37 \\
55 \\
30\end{array}$ & $\begin{array}{l}53 \\
55 \\
37 \\
72\end{array}$ & & & \\
\hline
\end{tabular}

${ }^{1}$ Measured rate determined directly from segments of dive profiles. Calculated average rate for dive estimated by dividing maximum depth by dive duration.

the bird's bouyancy was assisting. The descent rates in both birds observed were slower than ascent, and chamber observers were also impressed with the greater effort to swim down than up.

Swimming speeds. - These estimates were obtained by timing penguins as they swam between holes a known distance apart. Speeds were determined only after the birds had learned where the other hole was and had begun to swim directly to it after entering the water at the dive station. The fastest speed recorded was $9.6 \mathrm{~km} / \mathrm{hr}(5.2 \mathrm{mph})$ at which time the bird was averaging about $4.9 \mathrm{~m} /$ wingbeat (Table 4). Distance covered

TABLE 4

Swimming Vetocities and Wingbeat Frequency

\begin{tabular}{cccc}
\hline \hline Penguin & $\begin{array}{c}\text { Speed } \\
(\mathrm{km} / \mathrm{hr})\end{array}$ & Beat/min & Meters/beat \\
\hline H & 7.4 & & \\
& 7.6 & & \\
& 5.7 & & \\
& 9.4 & 49 & 2.8 \\
& 9.4 & 40 & 1.9 \\
& 5.4 & 30 & 3.0 \\
& 6.3 & 41 & \\
$\mathrm{I}$ & 7.8 & & \\
& 8.3 & 29 & 3.8 \\
& 8.5 & 24 & 3.9 \\
& 9.6 & 33 & 2.7 \\
& 6.3 & 31 & \\
\hline
\end{tabular}




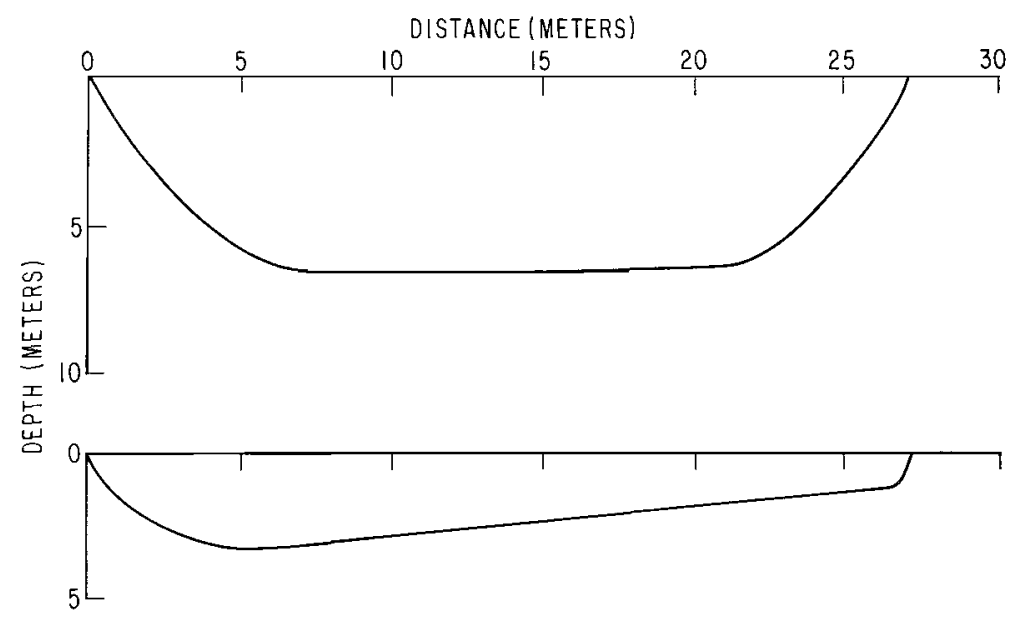

Figure 4. Dive profiles of a penguin swimming between two ice holes spaced $27 \mathrm{~m}$ apart. The ice thickness was about $1.5 \mathrm{~m}$. Profile depths represent distance below the under-ice surface.

per wingbeat varied considerably depending on whether measurement started while the bird was still accelerating or after it had reached a constant speed. During the trip from one hole to the other the bird usually swam at a shallow depth, saving time and effort (Figure 4). The lower profile of Figure 4 represents one of the fastest speeds the penguins made.

\section{RESPIRATION}

The respiratory pattern seems to indicate that recovery from dives is rapid (Table 5 and Figure 5). The respiration rate increases only slightly after dives of less than 1 minute, but the rates increase markedly immediately after dives of more than 1 minute. When a bird returns from a dive it hyperventilates vigorously. At this time inhalation is through the open mouth and exhalation is with the mouth closed. When resting in the water, the bird's breathing is very arrhythmic and the mouth remains closed. The pattern consists of a deep inspiration, followed by apneusis for a number of seconds. Expiration is a long sigh ended by another rapid, deep inspiration. Diving is usually preceded by a few rapid breaths and starts after what appears to be a deep inspiration. The birds were never seen to exhale under water.

\section{SHIVERING}

The Emperor Penguin's habit of breeding during the antarctic winter exposes it to extremely low temperatures. Stonehouse (1953) recorded 
TABLE 5

Dive Recovery Respiration Rates

\begin{tabular}{lllllll}
\hline \hline $\begin{array}{c}\text { Dive duration } \\
\text { (minutes) }\end{array}$ & & \multicolumn{5}{c}{ Minutes after Surfacing } \\
\hline$<1$ & & 1 & 2 & 3 & 4 & 5 \\
\hline$<1$ & $\mathrm{~N}$ & 5 & 3 & 3 & 3 & 3 \\
& $\mathrm{X}$ & 7.2 & 5.7 & 6.3 & 5.3 & 4.3 \\
$1-4$ & $\mathrm{R}$ & $5-10$ & $4-7$ & $4-10$ & $3-7$ & $3-6$ \\
& & & & & & \\
& $\mathrm{~N}$ & 19 & 14 & 7 & 4 & 4 \\
& $\mathrm{X}$ & 13.6 & 8.3 & 5.4 & 5.2 & 3.7 \\
$4-8$ & $\mathrm{R}$ & $7-22$ & $5-17$ & $2-9$ & $4-7$ & $3-5$ \\
& $\mathrm{~N}$ & 17 & 6 & 4 & 4 & 4 \\
$>8$ & $\mathrm{X}$ & 16.0 & 9.3 & 5.5 & 6.0 & 4.5 \\
& $\mathrm{R}$ & $12-25$ & $7-18$ & $5-6$ & $5-7$ & $3-5$ \\
& $\mathrm{~N}$ & 8 & 6 & 2 & 3 & 3 \\
& $\mathrm{X}$ & 14.7 & 13.7 & 7.0 & 5.7 & 5.0 \\
& $\mathrm{R}$ & $10-18$ & $6-23$ & & $5-6$ & $4-6$ \\
\hline
\end{tabular}

a low of $-35^{\circ} \mathrm{C}$ at Dion Islets rookery, Prévost (1961) one of $-30^{\circ} \mathrm{C}$ at the Pointe Geologie rookery, and we noted a $-45^{\circ} \mathrm{C}$ at Cape Crozier in September 1968, which is certainly not the lowest winter temperature that occurs there. Consequently, it was somewhat surprising that a bird considered to be so well-adapted to cold would show any signs of discomfort after relatively short periods of time in sea water of $-1.9^{\circ} \mathrm{C}$ (Table 6). Four out of six birds appeared to shiver sometime during the experiments. That this shivering was a response to cold rather than trembling from fright or nervous reaction to the experimental conditions is indicated by the fact that its onset did not occur as soon as they were placed in the water, with the one important exception of a molting bird whose feather coat was in poor condition and who began shivering immediately after entering the water. Normally Emperor Penguins do no swimming during the molt. It is also interesting to note that when much active diving was involved, the onset of shivering occurred later than when birds just rested in the water. Also, groups of birds observed diving in ice holes at Cape Crozier appeared to get out of the water at intervals and preen, suggesting that whenever possible the birds prefer not to stay in the water for long, continuous periods.

\section{ORIENTATION}

Vision.-We soon found that we had to exercise caution in conducting these experiments because the birds on occasion appeared to become disoriented under the ice. Dives of more than 9 minutes reflected this confusion and probably some of the shorter dives did also. Under-ice diving is not a unique experience for the birds, they not only dive under large floes 


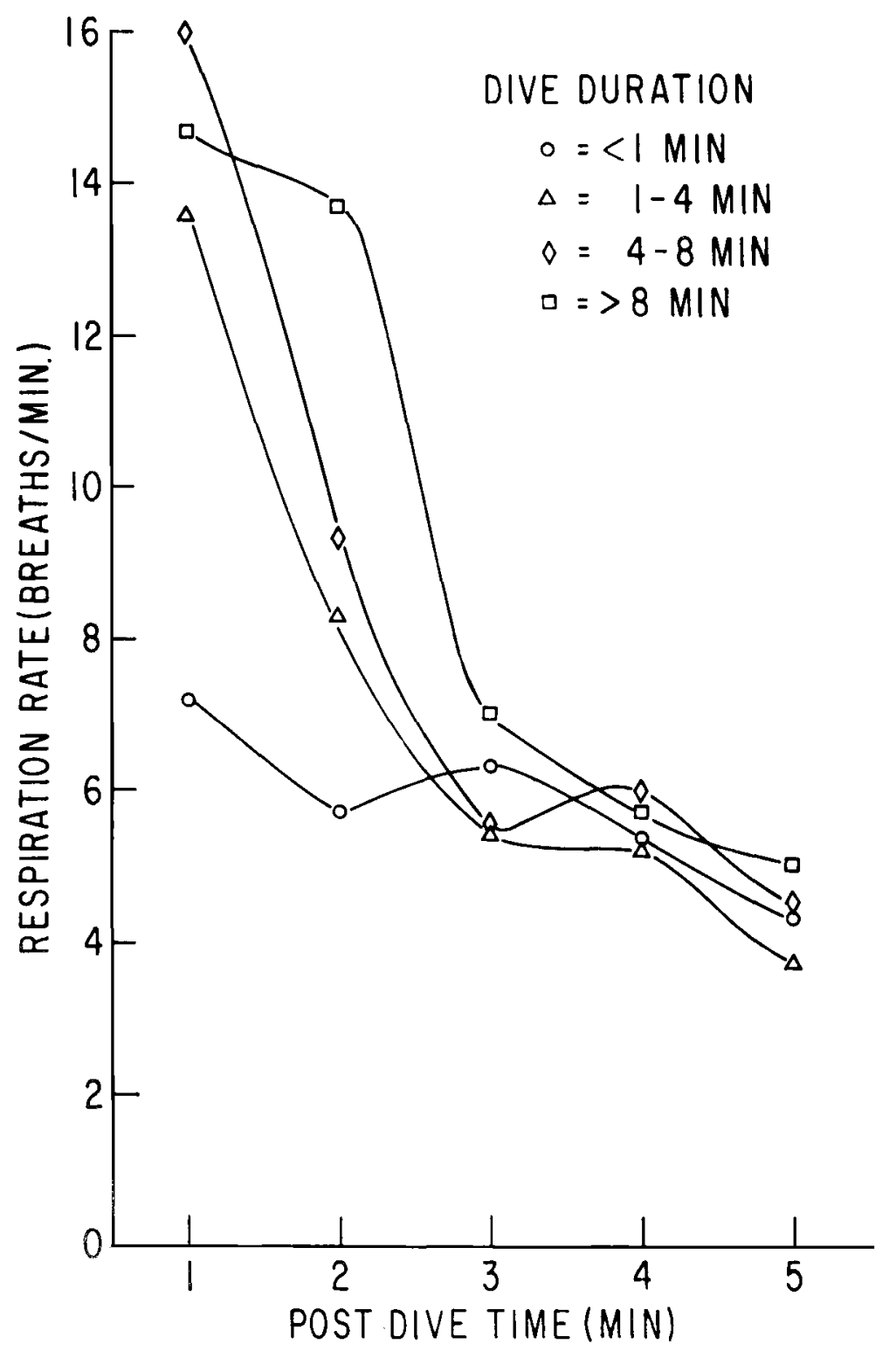

Figure 5. Post dive respiration rates. The first 2 to 3 minutes after the dive breathing is regular and deep. If the surface time goes much beyond 3 minutes respiration becomes arrhythmic with a sustained inspiratory phase. 


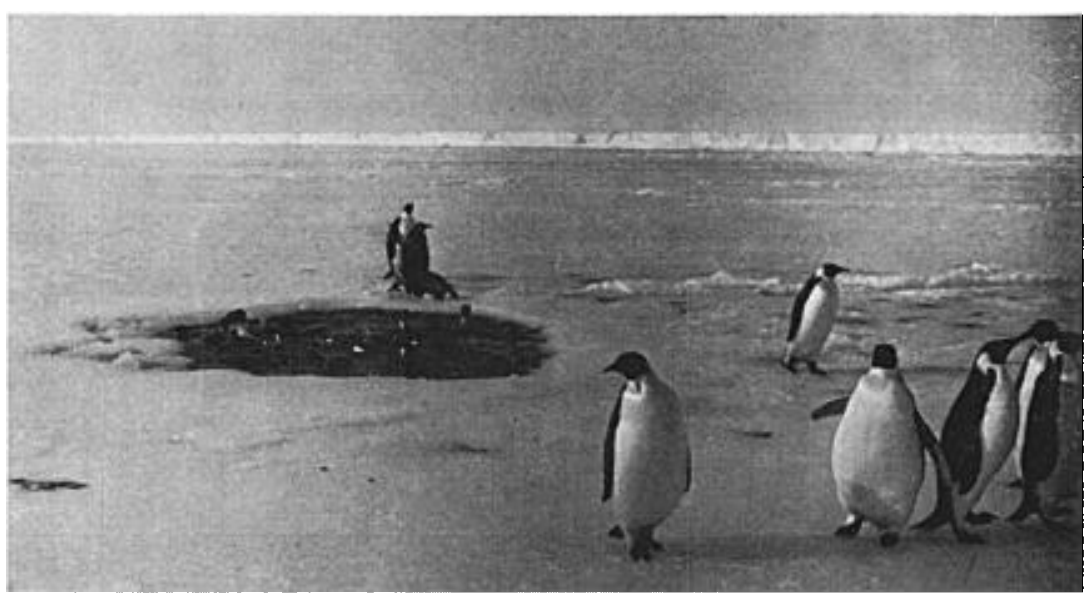

Figure 6. An isolated penguin hole about $1.5 \mathrm{~km}$ distant from the Ross Ice Shelf. The ice thickness at the hole was between $15-30 \mathrm{~cm}$.

in the pack ice, but we also saw them diving under a thin (ca. $30 \mathrm{~cm}$ thick) but extensive sea ice sheet at Cape Crozier. In this instance the birds were swimming between several isolated holes spaced from 240 to over $365 \mathrm{~m}$ apart (Figure 6). Some of the floes they dive under are no doubt several feet thick and probably in some situations they dive under thick fast ice through scattered open leads. During our experiments we saw birds make such errors as swimming forcefully beak first, into the bottom of thick ice. Often this was in places that lacked the platelet ice coat so the undersurface appeared brighter and apparently deceptively thin. One of our penguins was so determined to drive through the $2-\mathrm{m}$ thick ice that it selected places where there was a 1-m-thick layer of platelet ice collected on the undersurface as well. In this instance the bird actually disappeared out of sight as it penetrated through the soft platelet layer to the firm sea ice above it.

Once we recognized this orientation problem we took a number of precautions. Still it was remarkable to note that even though the sub-ice chamber, which was a prominent underwater reference point, was only 5-10 $\mathrm{m}$ from the station hole, birds that came to investigate the chamber were sometimes confused as to where the breathing hole was. In one case the bird was near the chamber, started to swim towards the hole, turned around, appeared uncertain, and slowly returned towards the chamber. A strong light was then directed into the water from the breathing hole and the bird immediately regained its bearings.

Acoustics.--Underwater recordings were made in two experiments 
TABLE 6

Onset of ShIvering after Water Entry

\begin{tabular}{|c|c|c|c|}
\hline Penguin & $\begin{array}{l}\text { Shivering onset time } \\
(\min )\end{array}$ & $\begin{array}{l}\text { Time in } \\
\text { water }\end{array}$ & $\begin{array}{c}\text { Number of } \\
\text { dives }\end{array}$ \\
\hline $\begin{array}{l}\text { Shivering } \\
\text { B } \\
\text { B } \\
\text { B } \\
\text { C } \\
\text { D } \\
\text { D } \\
\mathbf{M}^{\mathbf{1}}\end{array}$ & $\begin{array}{c}60 \\
34 \\
12 \\
100 \\
65 \\
60 \\
\text { Immediate }\end{array}$ & & $\begin{array}{r}7 \text { dives } \\
\text { No dives } \\
\text { No dives } \\
20 \text { dives } \\
27 \text { dives } \\
33 \text { dives }\end{array}$ \\
\hline $\begin{array}{l}\text { Nonshive } \\
\underset{\text { F }}{\text { G }}\end{array}$ & uals & $\begin{array}{l}46 \\
62\end{array}$ & $\begin{array}{r}5 \text { dives } \\
10 \text { dives }\end{array}$ \\
\hline
\end{tabular}

${ }^{1}$ Molting bird.

during the penguins' first diving experience at the station hole. Our equipment, Atlantic Research Corporation hydrophone and Martel taperecorder, had an estimated frequency response of $0.5-8 \mathrm{Khz}$. We noted no unusual sounds that might be attributed to the penguins, nor during our underwater observations did we see any indications of throat or body movements that suggested vocalizations.

\section{General Swimming Observations}

Group behavior.-Emperor Penguins are most often seen swimming as a group that in our experience seems to act as a fairly tight unit. The most extreme example of this unity was seen near the Cape Crozier rookery. The birds were diving at widely separated holes in very thin sea ice (ca. 15-30 cm thick). A group of birds would suddenly appear in the hole, almost in unison. Sometimes as many as 30 birds surfaced in a $3-\mathrm{m}$ diameter hole (Figure 7). Then, as if on command, they all dived. Our open water observations both at Cape Royds and Cape Crozier were similar. Our only underwater observation of birds swimming together was made near Cape Royds. The water depth was about $20 \mathrm{~m}$ and the birds swam as a group here also (Figure 8). In this case they often dived to the bottom and appeared to be searching under the scattered boulders.

Posture.-When swimming submerged penguins pull the head in close to the body (Figure 8). The wing excursion during the beat is great, the wing tips nearly touch on the upstroke and then come fully down to the sides. Between strokes, when the bird is gliding, the wings are extended laterally. The birds have remarkable maneuverability and can literally pivot on their wings as they flip over and reverse directions. 


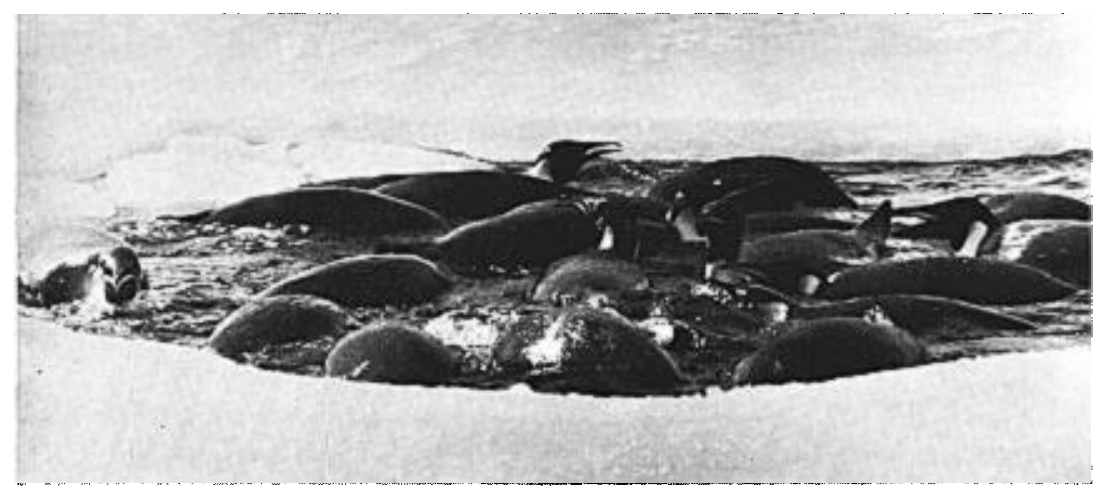

Figure 7. Emperor Penguins surfacing in breathing hole $3 \mathrm{~m}$ in diameter. Approximately 20 birds are shown, but as many as 30 birds at one time were counted in this hole.

Next to the wings the feet seem to be the most important guidance accessory. As the birds dive they kick their feet vigorously in unison, with the bottom of the foot facing dorsally. While cruising the feet may be held with the soles facing each other, or they may be turned with the soles up. When coming to the surface the feet are turned down into the normal standing posture and act as a brake. The tail seems to play a passive role as a fixed rudder.

The eyes are directed downward and apparently their best visual field is in this direction. There appears to be some overlap in the visual field in the frontal direction and even more so in the direction ventral to the beak that makes binocular vision possible. When birds approach each other closely or when a human approaches them they often raise the beak and look at the intruder from the lower portion of the head. When swimming under the ice they must tilt their heads to one side in order to see above. They were never noted to swim on their backs to make upward scanning easier.

Comfort movements.-One behavior pattern of uncertain function is what appears to be in-water feather conditioning. Such patterns have been described extensively in the Anatidae by McKinney (1965), and a comprehensive report of these movements in Adélie Penguins is in preparation (Ainley, pers. comm.). While surfaced the birds frequently roll onto one side, raise the uppermost flipper, and rake that side with the ipsilateral foot. This maneuver may serve the purpose of fluffing and combing water out of the feathers to maintain their insulative effectiveness. The behavior has been noted in Emperor and Adélie Penguins, both at the experimental dive hole and in open water; it has also been 


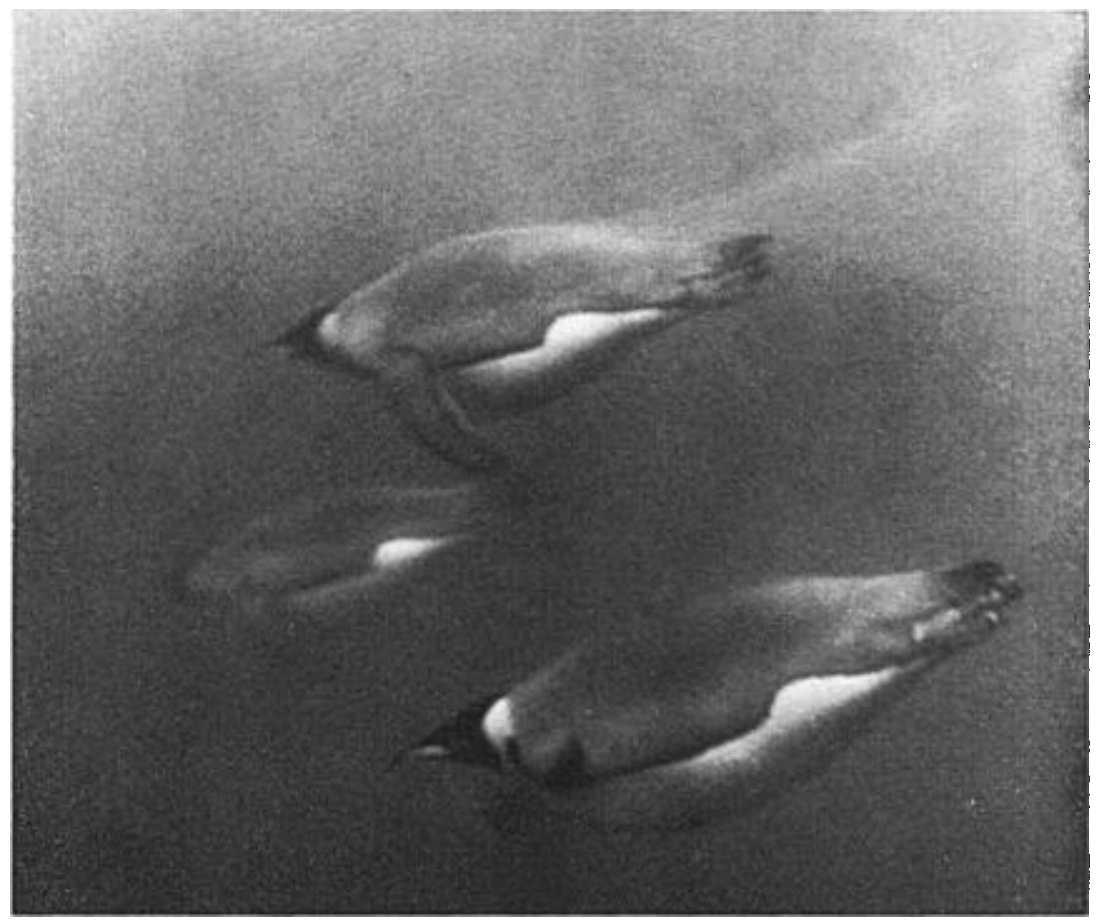

Figure 8. Three Emperor Penguins swimming underwater. Note the tucked in position of the head, attitude of the feet with soles directed upward, and nearness of birds to each other.

seen in Adélie Penguins in our laboratory pools at Scripps Institution of Oceanography where the water temperature is no lower than $56^{\circ} \mathrm{C}$.

\section{Discussion}

\section{SUbMERSION ENDURANCE}

The physiological adjustments to prolonged submersion in birds has been studied in a few species of birds, mainly the domestic duck. The major features of these adjustments have been reviewed recently (Andersen, 1966) and the similarities between birds and mammals are noted. Some of the more salient characteristics of those diving birds studied are: blood volume as a function of per cent body weight is greater than in terrestrial birds (Andersen, 1966); upon submergence a rapid and profound bradycardia develops (Bert, 1870; Scholander, 1940; Eliassen, 1960); stroke volume seems to remain the same (Johansen and Aakhus, 1963); cardiac output decreases and blood flow to the muscles is reduced (Johansen, 1964); and there is a depression of metabolic rate 
(Scholander, 1940; Pickwell, 1968). These parameters reflect a general circulatory redistribution that enhances asphyxial tolerance because those organs capable of extensive, anaerobic metabolism are isolated from the circulating blood oxygen, which is then conserved for such organs as the brain and heart that have a relatively low resistance to hypoxia.

Probably because of its availability the domestic duck has received a preponderance of attention, but rather interesting is the fact that although it is a shallow water feeder, it appears able to stay submerged longer than many of the true divers such as guillemots, cormorants, and some penguins. The longest experimental dive that a bird has recovered from was the forced submersion of a duck for 17 minutes where it had been trained not to exhale during the dive (Richet, 1899). By clamping the trachea this same investigator found that survival time in one duck was as long as 25 minutes. Forced submersions of the Macaroni Penguin, Eudyptes chrysolophus for 5 minutes and the Gentoo Penguin, Pygoscelis papua, for 7 minutes have been reported by Scholander (1940). The impression was that they were near their limit. Measured submersion durations of unrestrained divers are marked by their brevity. Dewar (1924) summarizes a number of species and no dives exceed 2 minutes.

No physiological experiments have been performed on diving Emperor Penguins, but a comparison of their submersion performance to those of other aquatic birds indicates that such studies would be of interest. A duration of 18 minutes is especially noteworthy considering that the bird was swimming actively during the dive. Emperor Penguin dive durations even compare favorably with those of some of the much larger marine mammals, such as northern fur seals (Callorhinus ursinus) and California sea lions (Zalophus californianus) (see Irving, 1964; Harrison and Kooyman, 1968 for summaries of submergence endurance). Consonant with this submersion capacity are the data on hemoglobin, the concentration of which is about $17 \mathrm{~g} / 100 \mathrm{ml}$ of blood (Lenfant et al., 1969). This is high compared with that of most birds and in fact is greater than in many diving mammals (Lenfant, 1969).

\section{Pressure Effects}

The deepest dive we measured of about $265 \mathrm{~m}$ is considerably greater than the 60-m depth reported for the common loon, Gavia immer, and the Old-squaw, Clangula hyemalis (Schorger, 1947), which are the deepest reported for other species to our knowledge. We have noted what we believe to be feeding dives under circumstances similar to our depthrecording experiments at Cape Crozier when we measured the deep dives. In these supposed feeding forays the birds were diving as a group, usually returning to the surface near where they originally submerged. 
Upon surfacing they often made head and neck motions suggestive of swallowing. Breathing is exceptionally heavy between dives of this kind. The diet of birds in the Cape Crozier area where most of these observations were obtained appears to be squid, based on the stomach contents of chicks found dead (LeResche, pers. comm.). Such a diet is significant because we believe squid in this area are primarily a deep-dwelling group.

The rapid rates of depth change and the diving depths we recorded in this study are of interest because of both the internal pressure equalization problems and gas absorption. So long as no obstructions between various gas cavities occur and some means exist of compensating for the internal change in gas volume, no equalization problem should develop. Volumecompensating mechanisms in the penguin have not been investigated. The lack of pneumatic bones in penguins is advantageous in a number of ways, one of which would be the elimination of the need for pressure equilibration. Unlike seals, which dive with little air, penguins seem to dive on inspiration and consequently have a large volume of air. This is of particular interest in light of Richet's (1899) experiments in which volume of air in a duck's lungs and air sacs during the dive seemed directly related to submergence capability. Andersen (1959) and Pickwell (1968) have shown that during submergence birds utilize the oxygen in the air sacs. Therefore one would expect gas absorption to increase with depth, which would seem to create a problem of blood oxygen regulation at depth and gas excretion upon rapid ascent. If so, a hazard of both anoxia and gas embolism exists. No experimental data exist relevant to pressure effects in birds. The little information available for diving mammals has been reviewed recently (Scholander, 1964; Kooyman and Andersen, 1969) and the existing evidence supports the hypothesis that in these animals probably little gas exchange occurs in the lungs during deep dives. On compression the structurally weak lung alveoli are thought to become much reduced if not atelectatic at depths as shallow as $30 \mathrm{~m}$ because of the high dead space to lung volume ratio and the rigidity of the bronchioles into which most of the alveolar gas is compressed. Because diving birds possess air sacs, they have a potentially much larger relative gas volume, and Emperor Penguins also dive on inspiration. Both of these properties would seem to be disadvantages to deep divers unless they have some responses to pressure different from those of diving mammals. Experiments on green sea turtles, Chelonia mydas, have shown that lung collapse and gas absorption occur (Berkson, 1967). In this study it was found that under certain conditions gas emboli did develop during deep diving.

The problems of anoxia during ascent from deep dives have been reviewed (Mithoefer, 1965; Schaefer, 1965), and the possibility that Emperor Penguins may utilize lung oxygen on deep dives raises the 
question of why they might not be susceptible to this condition. Increased pressure results in higher oxygen tensions within the lungs and blood. In man this enables him to extend his diving time while at depth; but as he ascends the oxygen tension may drop to an anoxic level resulting in unconsciousness. This risk is especially great if the swimmer hyperventilates before the dive, thus reducing $\mathrm{CO}_{2}$ tension and further lessening the urge to breathe at critical oxygen tensions.

\section{Temperature Regulation}

Maintenance of body temperature must require some exceptional adaptations in this species, not only for heat conservation, but for unloading excess heat during or after vigorous exercise. These problems have been reviewed recently by Stonehouse (1970) who summarizes what little is known about the thermal characteristics of Emperor Penguin plumage. The subdermal fat thickness is about $2 \mathrm{~cm}$ on the abdomen and back at the start of breeding, feather length is about $4 \mathrm{~cm}$, plumage thickness $1.0-1.5 \mathrm{~cm}$, and heat flux across a dried and salted skin is slightly less than for other penguins, a pattern consistent with the other values of plumage and fat thickness that are somewhat greater than for other penguins.

Circulatory anatomy of the extremities has not been studied, but they very likely have some kind of heat conserving circulatory adaptations such as counter-current blood flow similar to that described for the porpoise (Scholander and Schevill, 1955). Of interest here is the fact that one of our birds (D) cut its wing tip just before the diving experiments and blood was seen flowing freely from the wound for nearly 2 minutes of the first dive. Continued blood flow in such superficial vessels during diving could result in considerable heat loss unless there was some kind of heat conserving mechanism such as the above mentioned countercurrent flow. This bleeding is also of particular interest with regard to blood oxygen conservation. In Scholander's (1940) experiments with forced-dived penguins, blood flow to peripheral areas nearly ceased, indicating major peripheral vasoconstriction and vascular shunting of blood. The short duration of the dive (2 minutes 15 seconds) when we observed bleeding may indicate some elective ability in blood shunting during an anticipated short dive.

Variation in respiration patterns may also have a significant effect on the thermal balance of these animals. The long drawn-out breaths while resting in the water may result in considerably less heat lost per amount of oxygen consumed than the deep, open-mouthed, rapid breathing after extended dives. In addition, the short breath-holds between inspiration and expiration permit the resting bird to continue scanning underwater. 


\section{ORIENTATION}

Little information is available on swimming speeds in aquatic birds and mammals. One Adélie Penguin (Pygoscelis adeliae) that learned to swim between two breathing holes $120 \mathrm{~m}$ apart was timed at a rate of $7.2 \mathrm{~km} / \mathrm{hr}$. Weddell seals have been observed to swim between holes $1.9 \mathrm{~km}$ apart at an average speed as high as $10.4 \mathrm{~km} / \mathrm{hr}$ (Kooyman, 1968), and a trained porpoise (Stenella attenuata) was clocked at a top speed of $45 \mathrm{~km} / \mathrm{hr}$ for a few seconds (Lang and Pryor, 1966). The maximum swimming speed that we measured of $9.6 \mathrm{~km} / \mathrm{hr}(15.3 \mathrm{mph})$, if assumed to be a sustainable rate, means that the birds could swim a total distance of possibly $3 \mathrm{~km}$ during an 18-minute dive. Even while diving in heavy pack ice or under most other conditions that the birds may find themselves, this should be more than adequate for swimming between spaces in ice floes or between holes in thin ice. If they dive between far and widely separated holes in thick ice, the risks become much greater with the increasing problem of under-ice orientation.

Unlike the Weddell seal, which seems to have very exact under-ice orientation abilities and consistent patterns of diving and exploratory behavior (Kooyman, 1968), the Emperor Penguin appeared to have no such characteristics. In fact some of the erratic swimming behavior such as attempting to pierce forcefully through 2 -m thick ice gave quite the opposite impression. Yet as mentioned earlier, these birds must at times dive under ice and under very rigorous conditions, such as the antarctic night. Perhaps one important difference in our studies and the natural conditions is the advantage, as yet unstudied, of group diving.

We found no evidence of acoustic orientation, and visual cues seemed to be of utmost importance to our birds. Even when only a few feet from the hole, but in a position that resulted in the hole being visually obscured, the birds frequently seemed confused. During the swimming speed experiments one bird made 11 dives before finding another hole only $27 \mathrm{~m}$ from the original hole, and then only after a piece of $30-\mathrm{cm}^{2}$ foil was lowered into it. When the second bird was released the aluminum foil was already in place and the bird found the hole on the first dive. At Cape Crozier we watched groups of birds diving between scattered holes that were visually isolated from one another, which seems to suggest they need something more than vision for safe navigation. However these holes were so numerous that even during randomly deep diving below them the probability of coming to the surface near one seems great. Also the network of refrozen cracks and other discontinuities in the ice should have made good visual landmarks. 


\section{ACKNOWLEDGMENTS}

This study was supported by the National Science Foundation (NSF GA 4038 and GA 13713 to G. L. Kooyman and GA 1215 to R. Elsner) through the Office of Polar Programs and by NIH Career Development Award KE HE 7469 to R. Elsner. The grants were administered by the University of California, San Diego.

Special thanks are due to $\mathrm{H}$. K. Lee and W. Boggs for assistance in scuba; R. Allison for making available and helping us with the Adélie Penguins; and J. J. Wright, M. Saltveit, and D. Foster for help at Cape Crozier. U. S. Navy Air Development Squadron (VX-6) helicopter crews gave us outstanding support in the field, especially Lcdr. J. Brandau, who sustained a very painful injury while assisting us at Cape Crozier during the deep diving experiments.

\section{SumMary}

The diving behavior of the Emperor Penguin was studied by several means: 1) direct observation from the ice edge, 2) an observation chamber, 3) scuba, and 4) direct measurement of dive depths using two kinds of depth-recorders. Dive durations were determined for 238 dives and the maximum submergence was over 18 minutes. Of 40 depth measurements obtained, the maximum was $265 \mathrm{~m}$. The most rapid depth change rate was a short ascent of $120 \mathrm{~m} / \mathrm{min}$; during such maneuvers the birds' bouyancy seems to assist them greatly. Average swimming speed for birds between two holes $27 \mathrm{~m}$ apart ranged from 5.4 to $9.6 \mathrm{~km} / \mathrm{hr}$.

Respiration patterns and shivering varied considerably depending on the birds' activity. Respiration was deep and rapid after prolonged dives, whereas after short dives or while resting in the water it became slow with a very extended expiratory phase. The onset of shivering was much delayed in birds diving actively when compared to those just resting in the water.

During experimental dives single birds were often noticeably confused and uncertain of the location of the breathing hole. The birds seemed to rely on vision for under-ice orientation. Tape recordings were made during some dives, and the birds made no obvious vocalizations. In addition to the orientation observations, general swimming behavior of birds, such as group activity, posture, and maneuverability were noted.

\section{Literature Cited}

Andersen, H. T. 1959. A note on the composition of alveolar air in the diving duck. Acta Physiol. Scand., 46: 240-243.

Andersen, H. T. 1966. Physiological adaptation in diving vertebrates. Physiol. Rev., 46: 212-243.

Berkson, H. 1967. Physiological adjustments to deep diving in the Pacific green turtle (Chelonia mydas agassizii). Comp. Biochem. Physiol., 21: 507-524.

BERT, P. 1870. Leçons sur la physiologie comparée de la respiration. Paris, Baillière.

Dewar, J. M. 1924. The bird as a diver. London, Witherby. 
Eutassen, E. 1960. Cardiovascular responses to submersion asphyxia in avian divers. Arbok Univ. Bergen, Mat.-Nat., Ser. No. 2.

Fryer, D. H. 1958. Cartography and aids to navigation. Pp. 438-465 in A history of technology, vol. 5 (C. Singer, C. J. Holmyard, A. R. Hall, and T. I. Williams, Eds.). London, Oxford Univ, Press.

Harrison, R. J., and G. L. Kooyman. 1968. General physiology of the pinnipeda. Pp. 211-296 in The behavior and physiology of pinnipeds (R. J. Harrison, R. C. Hubbard, R. S. Peterson, C. E. Rice, and R. J. Schusterman, Eds.). New York, Appleton-Century-Crofts.

IRving, L. 1964. Comparative anatomy and physiology of gas transport mechanisms. Pp. 177-212 in Handbook of physiology, section 3: Respiration, vol. 1 (W. O. Fenn and H. Rahn, Eds.). Washington, D. C., Amer. Physiol. Soc.

JoHANSEN, K. 1964. Regional distribution of circulating blood during submersion asphyxia in the duck. Acta Physiol. Scand., 62: 1-9.

Johansen, K., AND T. Aakhus. 1963. Central cardiovascular responses to submersion asphyxia in the duck. Amer. J. Physiol., 205: 1167-1171.

Koovman, G. L. 1965. Techniques used in measuring diving capacities of Weddell seals. Polar Rec., 12: 391-394.

Koovman, G. L. 1968. An analysis of some behavioral and physiological characteristics related to diving in the Weddell seal. Antarctic Res. Ser., 11: 227-261.

Kooyman, G. L., and H. T. Andersen. 1969. Deep Diving. Pp. 65-94 in The biology of marine mammals (H. T. Andersen, Ed.). New York, Academic Press.

Lang, T. G., and K. Pryor. 1966. Hydrodynamic performance of porpoises (Stenella attenuata). Science, 152: 531-533.

Lenfant, C. 1969. Physiological properties of blood of marine mammals. Pp. 95110 in The biology of marine mammals (H. T. Andersen, Ed.). New York, Academic Press.

Lenfant, C., G. L. Kooyman, R. Elsner, and C. M. Drabek. 1969. Respiratory function of the blood of the Adélie penguin, Pygoscelis adeliae. Amer. J. Physiol., 216: $1598-1600$.

McKinney, F. 1965. The comfort movements of Anatidae. Behaviour, 25: 120-220.

Mithoefer, J. C. 1965. Breathholding. Pp. 1011-1026 in Handbook of physiology section 3: Respiration, vol. 2 (W. O. Fenn and H. Rahn, Eds.). Washington, D. C., Amer. Physiol. Soc.

Pickwell, G. V. 1968. Energy metabolism in ducks during submergence asphyxia: assessment by a direct method. Comp. Biochem. Physiol., 27: 455-485.

PrÉvosT, J. 1961. Ecologie du manchot empereur. Paris, Hermann.

RICHE', C. 1899. De la résistance des canards à l'asphyxie. J. Physiol. Pathol. Gen., 1: 641-650.

SchatFrer, K. E. 1965. Circulatory adaptation to the requirements of life under more than one atmosphere of pressure. Pp. 1843-1874 in Handbook of physiology, section 2: Circulation, vol. 3 (W. F. Hamilton and P. Down, Eds.). Washington, D. C., Amer. Physiol. Soc.

SCHOLANDER, P. F. 1940. Experimental investigations on the respiratory function of diving mammals and birds. Hvålradets Skrifter; Norske Vikenskaps Akad. Oslo, 22: 1-131.

Scholander, P. F. 1964. Animals in aquatic environments: diving mammals and birds. Pp. 729-739 in Handbook of physiology, section 4: Adaptation to the environment. (D. B. Dill, Ed.). Washington, D. C., Amer. Physiol. Soc. 
Scholander, P. F, ANd W. E. Schevill. 1955. Counter-current vascular heat exchange in the fins of whales. J. Appl. Physiol, 8: 279-282.

Scrorger, A. W. 1947. The deep diving of the loon and the Old-squaw and its mechanism. Wilson Bull., 59: 151-159.

Stonenouse, B. 1953. The Emperor Penguin Aptenodytes forsteri. 1. Breeding behaviour and development. Falkland Islands Dependencies Surv., Sci. Rept. No. 6: $1-33$.

Stonemouse, B. 1970. Adaptation in polar and subpolar penguins (Spheniscidae). Pp. 526-541 in Antarctic ecology, vol. 1 (M. W. Holdgate, Ed.). London, Academic Press.

Wilson, E. A. 1905. On the whales, seals, and birds of Ross Sea and South Victoria Land. Pp. 469-492 in The voyage of the discovery (by R. F. Scott) vol. 2, appendix 2. London, Smith, Elder and Co.

Physiological Research Laboratory, Scripps Institution of Oceanography, University of California, San Diego, La Jolla, California 92037. Present address of second author: Department of Biological Sciences, University of Arizona, Tucson, Arizona 85721. Accepted 9 June 1970. 